\title{
XII. Observations on the magnetic property of cobalt and nickel. Extracted from a memoir read in the French National Institute
}

\section{B.G. Sage}

To cite this article: B.G. Sage (1802) XII. Observations on the magnetic property of cobalt and nickel. Extracted from a memoir read in the French National Institute, Philosophical Magazine Series 1, 13:49, 58-59, DOI: 10.1080/14786440208676091

To link to this article: http://dx.doi.org/10.1080/14786440208676091

曲 Published online: 18 May 2009.

Submit your article to this journal $\pi$

Џll Article views: 3

Q View related articles $\sqsubset$ 


\section{$\left[\begin{array}{ll}5^{8} & ]\end{array}\right.$}

XII. Obfervations on the Magnetic Property of Cobalt and Nickel. Extracted from a Memoir riad in the Frencb National Inftitute by B. G. SAGt, Direstor of the firft Scbool of Mines*.

$\mathrm{H}$

ANG refolved to repeat the experiments by which Klaproth, Taffaert, and Haüy determined that cobalt and nickel are fufceptible of acquiring magnetic properties, I proceeded to refine thefe femi-metallic fubftances by means which I thall here defcribe, and by which I extracted from cobalt the arfenic, iron, bifmuth, and filver; fubftances with which it is almoft always combined.

Having difengaged the arfenic, by torrefaction, from cobalt ore of a whitith gray colour, I mixed pounded charcoal with the oxide or brownifh calx which remained in the teft. I then torrefied it a fecond time, in order to difengage the arfenical acid.

I then mixed this oxide of cobalt with two parts of vitreous flux $t$ and a little pulverized charcoal. I fufed this mixture, and obtained a button of cobalt, which $I$ again fufed with borax : after thefe two fufions the cobalt exhibited a homogeneous grain, though it contained iron, bifmuth $\ddagger$, and particularly filver, in the ratio of nearly a fourth.

I pulverized this cobalt, and, having mixed it with an equal part of fal-ammoniac, fubjected it to difillation: cauftic volatile alkali was difengaged, and there was afterwards fublimed in the neck of the retort fal-ammoniac coloured yellow by a little iron. The next fublimated portion had a pale green tint, a colour which arofe from the cobalt. The retort having been kept in a red heat for an hour, falt or muriate of bifmuth was fublimated in white foliaceous cryftals. This falt, when put into difilled water, was decompofed, and rendered it milky.

I mixed the muriate of cobalt which remained in the retort with fal-ammoniac, and proceeded to difillation: the fal-ammoniac, which was fublimated, contained neither iron nor muriate of bifmutb, and was coloured of a delicate green by a little cobalt.

I fufed the falt or muriate of cobalt which remained in the retort with equal parts of black flux and a fiftieth of pulverized charcoal: in this alkaline flux I found the cobalt

* From the Fournal d: Phyfogue, Floreal, an. 10.

+ Compofed of equal parts of whire glafs and fixed alkali.

$\ddagger$ If this metal be in the ratio of a third, it diffufes itfelf around the bution of cobalt, and inclofes it as if it were tet in it.

and 
and filver in contact with each other, but without adhefion*.

It was this purified cobalt which I employed to difcover whether it was fufceptible of acquiring polarity by the magnet; and to afcertain it fully, I begged our colleague Coulomb, who is fo familiar with thefe experiments, to have the goodnefs to affit me. I carried to him the ingots of puritied cobalt and nickel, which he endeavoured to magnetize; but, as they did not indicate any magnetic property in a fatisfactory manner, he defired me to fufe them into thin plates, which I accordingly did. They were then eafily magnetized, and, being fufpended merely by a filk thread, indicated the poles in a perfect manner. Thefe facts prove that thefe two femi-metallic fubftances have, as well as iron, the faculty of retaining the magnetic fluid introduced into their pores.

XIII. Experiments and Obfervations on the Heat and Cold produced by the mechanical Condenfation and Rarefaction of Air. By John Daltont.

$\mathrm{I}_{\mathrm{F}}$

F a thermometer be inclofed in a receiver and the air fuddenly condenfed, the thermometer rifes a few degrees above the temperature of the atmofphere; and if the air be exhaufted from a receiver inclofing a thermometer, the mercury finks a few degrees immediately; but in both cafes after fome time it refumes its former ftation. 'Thefe facts are well known to philofophers of the prefent age, but they do not all agree in the explanation of them. Thinking the fubject worthy of elucidation, I was induced to inftitute a feries of experiments for the purpofe, which $I$ apprehend have led to a clear demonttration of the caufe of the phænomena, and moreover make the facts themfelves appear in a fomewhat different point of view from what they are feen in at the firft moment.

One circumftance is very remarkable, that whether the mercury rifes or falls in thefe inftances, it is done very rapidly; whereas in the open air, if a thermometer be only two or three degrees above or below the temperature, it moves very flowly. This feems to have fuggefted to every one the idea that the elafticity of the glafs bulb of the thermometer has a principal thare in producing the effect, by

* I purified the nickel from the iron it contained by fublimation with fal-ammoniac, and reduced it by fufng it with black flux.

f From the Marcbejter Memoirs, vol. v, part 2. 